\title{
Integrated Water Resources Management of Maetang Sub Watershed, Chiang Mai Province
}

\author{
Thunyawadee Sucharidtham $^{1 *}$, Thanes Sriwichailamphan ${ }^{2}$ and Wichulada Matanboon ${ }^{3}$ \\ ${ }^{1}$ Department of Applied Economics, National Chung Hsing University, Taiwan \\ ${ }^{2}$ School of Economics, Chiang Mai University, Thailand \\ ${ }^{3}$ Social Research Institute, Chiang Mai University, Thailand
}

\begin{abstract}
Thailand has been managing water in order to solve the water problem in the country for a long time. In 2011, however, Thailand suffered a severe flood, and that means the country's water management was not successful. Maetaeng watershed is another area that has been receiving a lot of funding to develop and solve the problem of water resources in the area continuously. Still, it was also found that the projects and budgets spent still cannot fix the problems of water resources in the area. This study aims to analyze the events, problems, and factors that can lead to the process development of integrated water resources management in Mae Taeng watershed area, Chiang Mai province. This qualitative study workshop was conducted by collecting basic information, setting a discussion panel for water users, and a workshop to brainstorm for the ideas of water management. The findings showed important factors positively affect the strength of the community, cooperation in water management of the community, and the sacrifices of strong community leaders. The negative impacts include the deforestation of certain ethnic groups, cultural diversity, a lack of awareness in the role of community leaders, as well as insufficient funding.
\end{abstract}

Keywords: Flood; Water resources; Watershed area; Chiang Mai province

\section{Introduction}

Thailand's water management issue is a longstanding problem entering into a crisis both quantitatively and qualitatively. Many areas in the country are experiencing an imbalance of supply and demand of water. In addition, water management in Thailand has not been successful enough due to many reasons: (1) the policy and water resources management plans in each government are not clear, not covering all relevant aspects. They also could not be concretely practiced; (2) there is also an organizational structure problem for water resources management. This is because Thailand has many offices responsible for the problem, but there are all under many ministries, so the work lacks of unity, is complicated, and has no direct responsible agency; (3) Another problem is the budget issue. Having too many national agencies causes problems in budget allocation, which could not be considered without fundamental solutions integrated in the overall plan; (4) Regarding legal issue, it is found that the current laws related to water resources are numerous and outdated. There are also gaps in between, and the laws lack the unity and are not suitable for the environment. The final problem is about the information technology [1-3]. Although Thailand has many water resource agencies, there are no information links and collection in the same place causing complexity in the preparation of the data. The information in each area is not complete and scattered in various government agencies without a clear and modern linkage system. As mentioned earlier, it can be seen that Thailand's water management agencies include national and local levels, and they have been trying to solve the problems caused by the use of water resources. However, it seems that the use of those efforts is not successful and still cannot sustainably resolve the issue of the use of water resources in many areas. Chiang Mai is one of the large provinces; however, the problem of water management still remains due to the population and economic growth. These factors lead to the demand for water in various activities. Although it has various water resources development projects in the Mae Ping river basin, such as Mae Ngat Somboonchol and Mae Kuang Udomtara dams, today, the demand for water activities increases for consumption, goods, agriculture, industry and service sectors. The reservoirs available today are unable to store enough water to meet such demand. Meanwhile, Mae Taeng watershed, a subwatershed of the Mae Ping river basin, covering in three districts of Chiang Mai, Wiang Haeng, Chiang Dao, and Mae Taeng district, has developed and resolved of water resource problems by using enormous amounts of funding from related agencies- the Department of Water Resources, Irrigation Department, and local authorities. Still, it was also found that such effort cannot resolve the issue of water resources in the Maetaeng river basin. As mentioned above, it showed inefficiencies in water management in Thailand. Therefore, it is necessary to conduct a study to systematically analyze the problem [4] of the country's water management starting from the present process of water resource management, scenario analysis, trends of water resource utilization, and problems of using water resources. The study process must focus on the participation of all concerned sectors. The purpose of this study is to analyze the factors that can lead to problems in the process development of integrated water resources management in order to meet the objectives. The researchers chose to study in the area of Maetaeng subwatershed, Chiang Mai province, so as to solve the problem of water resources use concretely and effectively, as well as to encourage people in the area to preserve and manage natural resources systematically and the integration of all sectors involved for sustainability.

\section{The Study Area}

This study chose the study area of the Maetaeng watershed which

*Corresponding author: Thunyawadee Sucharidtham, Department of Applied Economics, National Chung Hsing University, Taiwan, Tel: 886-979-286-598; E-mail: thunyawadee@gmail.com

Received June 24, 2015; Accepted July 24, 2015; Published August 07, 2015

Citation: Sucharidtham T, Sriwichailamphan T, Matanboon W (2015) Integrated Water Resources Management of Maetang Sub Watershed, Chiang Mai Province. J Glob Econ 3: 150. doi:10.4172/2375-4389.1000150

Copyright: () 2015 Sucharidtham T, et al. This is an open-access article distributed under the terms of the Creative Commons Attribution License, which permits unrestricted use, distribution, and reproduction in any medium, provided the original author and source are credited. 
is approximately 1953.90 square kilometers or $1,221,188$ rai covering three districts of Chiang Mai- Wiang Haeng, Chiang Dao and Maetaeng district- in subdistricts as follows $[5,6]$.

a) Wiang Haeng district covering three subdistrict, 22 villages as follows.

(1) Piang Luang subdistrict, which includes six villages, from Moo 1 to Moo 6, located in Maetaeng subwatershed.

(2) Mueang Haeng district, which includes 11 villages, from Moo 1 to Moo 12, except for Moo 6 that is not located in Maetaeng subwatershed.

(3) Saen Hai subdistrict, which includes five villages, from Moo 1 to Moo 5, located in Maetaeng subwatershed, and three subdistricts in Wiang Haeng district were studied.

b) Chiang Dao district covers six subdistricts, 12 villages, as follows.

(1) Chiang Dao subdistrict has only one village located in Maetaeng subwatershed, Moo 10.

(2) Thung Khao Phuang subdistrict has only one village located in Maetaeng subwatershed, Moo 6.

(3) Mueang Khong subdistrict has six villages located in Maetaeng subwatershed, Moo 1-Moo 6. As a result, this study used Mueang Khong subdistrict as an area of study since its villages involve with Maetaeng subwatershed the most.

(4) Mueang Ngai subdistrict has only one village located in Maetaeng subwatershed, Moo 6 .

(5) Mueang $\mathrm{Na}$ subdistrict has two villages located in Maetaeng subwatershed, Moo 2 and Moo 9.

(6) Mae Na subdistrict has only one village located in Maetaeng subwatershed, Moo 12 .

c) Maetaeng district covers eight subdistricts, 36 villages, as follows.

(1) Guert Chang subdistrict has eight villages located in Maetaeng subwatershed, from Moo 1 to Moo 8.

(2) Ban Chang subdistrict has two villages located in Maetaeng subwatershed, Moo 1 and Moo 2.

(3) Pa Pae subdistrict has five villages located in Maetaeng subdistrict, Moo 5, 6, 8, 9, and 10 .

(4) Mueang Kai subdistrict has five villages located in Maetaeng subwatershed from Moo 1 to Moo 5.

(5) Maetaeng subdistrict has seven villages located in Maetaeng subwatershed from Moo 2 to Moo 9.

(6) San Mahaphon subdistrict has six villages located in Maetaeng subwatershed from Moo 2 to Moo 7.

(7) Inthakhin subdistrict has only one village located in Maetaeng subwatershed, Moo 18.

(8) Khi Lek subdistrict has two villages located in Maetaeng subwatershed, Moo 1 and Moo 2.

Four subdistricts in Maetaeng district was selected for this study: Guert Chang, Maetaeng, San Mahaphon, and Khi Lek subdistrict.

In Maetaeng subwatershed, Maetaeng is the main river with 29 branches, and only those with 10 kilometers long are considered (Figure 1).

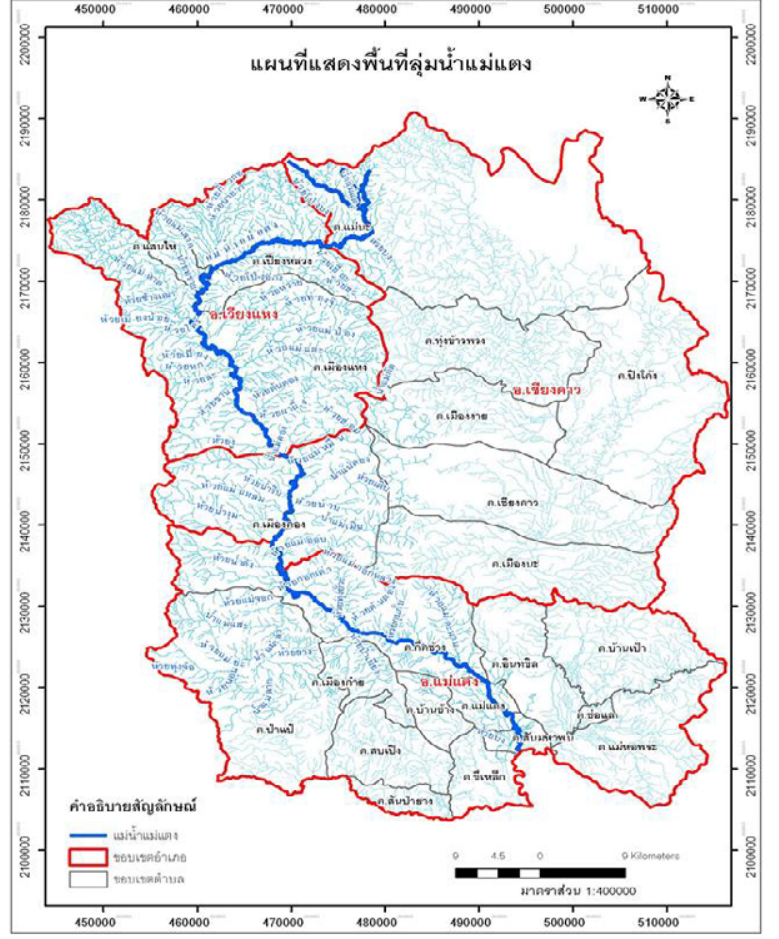

Figure 1: Map of Maetaeng Subwatershed from Mae Na Subdistrict, Chiang Dao District Watershed Area to the Ping River in San Mahaphon Subdistrict, Maetaeng District.
1) Nam Mae Khong
2) Huay Nam Dang
3) Huay Mae Hard
4) Huay Mae Tae
5) Huay Mae Hom
6) Huay $\mathrm{Ha}$
7) Nam Mae Lao
8) Huay Hong Ju
9) Nam Ngum
10) Huay Mae Jok Luang
11) Huay Mae Pong
12) Huay Tham $O$
13) Huay Ton Tong
14) Huay Mae Plaem
15) Nam Mae Muen
16) Huay Mae Jok Noi
17) Huay Mae Pam
18) Huay Khrai
19) Huay Ngu
20) Huay Kup Kap
21) Huay Mae Pla Sao
22) Huay Mae Kok Luang
23) Huay Mae Ka
24) Huay Mae Mong
25) Huay Mayommen
26) Nam Mae Sae
27) Huay Mae Salaluang
28) Huay Mae Kok
29) Huay La

\section{Concept and Participatory Management Principle}

The purpose of this study is to perform the integrated management of water resourcess focusing on public participatory management, as well as from related agencies [7-11]. The participatory management must begin with an understanding of management concept and process, basic elements of the management process in order to understand the principle better. Fayol suggested seven steps of management process called "POSDCORB" which is widely accepted and applied in agency management process: (1) Planning $(\mathrm{P})$ which is a program operational plan and procedure that have to be done in advance, (2) Organizing (O) which defines the structure of the agency, the allocation of the work structure, different positions, and clear authority, (3) Staffing (S) which is a human resource management, including recruitment, organization, 
staff promotion and development, staff encouragement, welfare, and working environment development, (4) Direction (D) which is a diagnostic command, control, command, and operation control, (5) Coordination (Co) which is to coordinate activities of the agency in order to promote good cooperation that leads to the common goal, (6) Reporting (R) which is a report of the personnel performance in different departments in order to inform the executives and members of the agency of the movement and progress of the mission regularly, and (7) Budget (B) which is the management of budget, expense account, and financial and property control and inspection. Three basic elements of the management process are: (1) Planning or sometimes refers to System Planning which consists of determining goals, objectives, strategies of understanding the resources that must be managed, and the expected outcomes of the implementation and determination of the factors that will enhance their performance; (2) Implementation or system programming which refers to agency management service in order to become efficient, effective, and economical at all sides for the best outcomes; and (3) Monitoring and Evaluation which is to measure and evaluate the activities of the operation by analyzing data obtained, and propose improvement if problems are found. The management starts from agency planning by allocating resources and activities to meet the goals and objectives for the required targets [12]. These monitoring and evaluation help to know if the implementation is successful as planned. The concept of participatory management of the public is that the management is so sensitive but necessary, so the involvement of the public must be planned step by step, and must have problem and success evaluation [13]. After that, the results should be adapted for the implementation of the next step according to the situation. These focus on two parts as follows: 1) the heart or the basic principle of management of the public participatory management the project manager must follow a $4 \mathrm{~S}$ principle: (1) Starting Early which is the public participatory process that must start early, and this includes providing information, stimulating ideas and comment hearing public opinion before making a decision; (2) Stakeholders which allows the public to participate extensively whether they are those affected in all sectors both directly and indirectly; they all have the opportunity to enter into a participatory process; (3) Sincerity which the project owner agency or authorizer must organize the process with sincerity, openness, honesty, without bias and with two-way communication at all times; and (4) Suitability which is a technique or pattern of appropriate public participation by considering the type and size of project, the variety and difference of the area, the stakeholder groups, as well as cultural differences, society, and values. 2) The effective public involvement should include planning which consists of three major steps: (1) Preparation which must be determined by the team or the person responsible in order to monitor the situation inside the responsible organization for decision making; (2) Planning from data in the preparation process which must be analyzed by the team in order to plan the public involvement; and (3) Steps leading to practice which is an action plan of each participatory activity, such as a public forum to decide where to organize or who the speaker should be $[14,15]$. In summary, Administration is a planning process, organization managing, directing and controlling, and operating within an organization. Participation means that an individual of each level practices by participating in the planning, organizing, directing and controlling the performance of each part fully, so the participatory administration is the way people in or outside the organization work together to achieve the goals effectively [16]. As a result, the participation in any stage must be based on criteria of knowledge, ability, experience, organizational limitations of the implementation process of the administration.

\section{Data Analysis}

This study employed operational data analysis in order to achieve the three objectives by using observation, interview, and focus group techniques. The data were monitored, processed, analyzed, and concluded using findings of the study, which was conducted from examining general condition of the area, situation, and the problems related to water resources in the Maetaeng watershed area [17]. After that, the data were processed and analyzed to identify the factors leading to the development of an integrated water resources management following five aspects as follows:

1) Integrate stakeholders from the use of all water resources in the basin.

2) Integrate related resources (soil, water, forest, and people).

3) Integrate resource management of stakeholder groups such as budget, personnel, etc.

4) Integrate water resources management process.

5) Integrate academic knowledge in the management of water resources.

Use descriptive analysis such as content analysis, network analysis, and causal analysis to interpret, describe, and draw conclusion from the data, as well as present findings in order to obtain the complete findings according to the research objectives [18-20].

\section{Discussion and Policy Recommendations}

\section{Discussion}

This study examined in the Maetaeng river area covering three districts: Wiang Haeng, Chiang Dao, and Maetaeng district by using observation, in-depth interview, focus group, and workshops held at district level, and study tour at a successful model community in water resources management [21]. The target group of the study was those who use water resources: the local government executives, heads of sub districts and villages, heads of irrigation, heads of water user group, farmer inspectors, farmers, relevant agencies, and entrepreneurs in the area, etc. This was to get the answers for the study and meet the intended objectives. It was concluded as follows.

\section{Water management in Maetaeng district}

Factors leading to integrated water resources management: Water management in each area differs due to the context areas and groups of people. The various factors involved in water management in the area of Maetaeng district is a clear network of water management by forming a water management committee among the water users. The factors leading to water management are as follows.

- The community should have a strong and loving harmony, participation, and play an important role to manage water in the area, according to the regulations set.

- The leaders in the area is another factor that affects the water management. They can be local administrators, subdistrict and village heads who must have the same perception and perspective, vision or common interest [22]. Moreover, they should work well together in the recognition and management of common problems, strengthen each other, promote interdependence, and interact in terms of collaborative learning. Thus, the strength of leadership is a key factor leading to water management that has the least problems [23].

- The committee should have a clear network operation covering the 
group of water users from the upstream, midstream and downstream and from Maetaeng, Mae Rim, down to San Patong district. The network has taken a role to participate in water management, meeting, and discussion among staff in order to develop or solve problems in various aspects.

- Agencies such as the Department of Irrigation has played a role in water management together with the community. Also, local governments has involved in some budgeting, such as the distribution of sandbags in flood season, including other water management budgets as requested [24].

- Operators in tourist attraction areas do not live in the area, especially at Guert Chang subdistrict. However, most of them are from outside coming to run businesses. The impacts arising from the tourism affect the ecosystems both on land and water [25]. These private operators have taken part in recognizing the problems, and have a role in solving water problems and water management together. Therefore, these entrepreneurs of travel businesses are also an important factor in the management of water.

Integrated water resources management process: The development model of water management in Maetaeng district is a changing form of management development according to the time and the problems. After this project had started to collect data, explained about the activities, organized workshops, as well as organized study tours for leaders, and exchanged knowledge of water management in other areas, it created new ideas for the water users and they also asked to become a leader in the development of an integrated water management [26]. They established the network together, which led to coordination with water management agencies, organizations, local governments in each area, local leaders, and entrepreneurs in the community, mobile development unit, Department of Irrigation, farmers, and related agencies. These groups took part in the exchange of knowledge [27-29]. In practice, after brainstorming the leaders, it can be concluded that the directions for future water management in Maetaeng district requires coordination with Subdistrict Administrative Organizations (SAOs) to help deepen canals seriously, provide surveillance of state projects coming into the area by using community power network, and funding to help prevent and resolve the impact of such projects. Furthermore, Maetaeng district should cooperate with private sectors having businesses that affect the community, collaborate between the community, related government agencies, private sectors, entrepreneurs, water user association, local administrative organizations, and ask for the cooperation of subdistrict administrative organizations or municipalities, or any shopping areas in the community to treat waste water before discharging into natural water resources. Additionally, the network has expanded within Maetaeng district, Guert Chang subdistrict, from three-district network-Maetaeng, Mae Rim, and San Patong district. Integrating approach of Guert Chang Subdistict Administration Organization cooperation was that they formed a committee among Maetaeng and Guert Chang Subdistrict Administrative Organization, and local government administrators in each area to join as a president and cosponsors [30]. Then they expanded the network to the outside area, that is, Chiang Dao and Wiang Haeng district, and linked the network to the region upstream area, Mueang Khong, Chiang Dao district, and Mueang Haeng, Saen Hai, Piang Luang subdistrict, Wiang Haeng district, by holding a monthly or quarterly meeting since the use of upstream, midstream, and downstream water needs to be integrated and solve problems together. Also, the network meeting must be held to gather problems and find solutions mutually, such as finding additional network, and cooperating with related agencies to provide funding continuously and sustainably.

\section{Water management in Chiang Dao district}

Factors leading to integrated water resources management: Water management in each area differs according to the context of areas and groups of people. For Muaeng Khong subdistrict, Chiang Dao district, it was found that factors or stimuli contributing to the integrated management of water resources in the area are as follows.

- Invasion of some ethnic groups in the area caused deforestation in the upstream area. In the past, there was no agency taking part in the discussion or solving the problem of deforestation on highlands [31]. The behavior of these ethnic groups affects the lives of people living downstream causing drought in the area. As a result, the invasion of the ethnic groups is a very important factor that contributes to water management in Chiang Dao district, especially in Mueang Khong subdistrict.

- Floods in rainy season is another important factor since the occurrence of flood brings sediment into the river resulting in shallow river. In addition, there are no river dams to stop the water, so the villagers suffer from flood problems annually. However, this problem has not seriously been addressed.

- In the past, the role of community leaders, such as subdistrict administrators, village heads, and community leaders, lacked participation in problem solving, and managing water seriously. Therefore, the role of community leaders is extremely important to contribute to the development of model and water management effectively and sustainably [32].

- Mueang Khong district still lacks of funding to solve the problem of water resources, especially the budget for the dams because most of them are made of natural materials. In rainy season, when flooding problems occur, these dams will be swept away while the existing concrete dams are in poor conditions, and there is no budget for maintenance, as well as for deepening the canals.

The process of integrated water resources management: The development model of water management in Mueang Khong subdistrict is a changing development model of management according to the time and problems. After this research project started to collect data, trained, organized activities, workshops, study tours for community leaders, and held stages for exchanging knowledge of water management in other areas, these helped develop approaches of integrated water resources management among users and community leaders at Mueang Khong subdistrict by encouraging establishing a network similar to the one in Maetaeng district [33]. For the model development and direction of water management in Mueang Khong subdistrict, water user groups and local leaders at various levels suggested that the direction of water management should be addressed in a broader view of water use. Not only looking at the problem, maintaining the forest should also be focused by creating the involvement of government agencies to solve invasion problems, asking for cooperation from the Forestry Department to oversee forest reserves, raising awareness of community leaders to educate people in the community to conserve the upstream forest, explain and teach people living on highlands to reduce deforestation from some ethnic groups in the upstream areas. In addition, funds should be provided to build standard dams to prevent flooding, and a network of five partners need to be formed in the community, which includes subdistrict administrators, village heads, local leaders, related government officials, and people living in the 
community to participate in problem solving and water management by having Subdistrict Administrative Organizations as the main host [34]. Moreover, subdistrict administrators and village heads should be requested to hold a monthly meeting in order to report problems people living in the area and nearby villages.

\section{Water management in Wiang Haeng district}

Factors leading to integrated water resources management: Water management in each area differs according to area and people context. The factors or stimuli leading to integrated water management in Wiang Haeng are follows.

- With conditions and problems of the current global warming becoming more intense, rainfall pattern fluctuation, deforestation, lack of budget for problem solving and disaster prevention, these result in drought. Wiang Haeng district often suffer from water shortages both for agriculture and water consumption. During the rainy season, it has suffered from the flood causing a lot of damage and suffering to the people. As a result, water management is going to be difficult because it is uncontrollable, and hard to predict disasters in advance. Of such issues, the villagers began to realize, and try to find ways to manage water together [35].

- Wiang Haeng district has many ethnic groups causing problems of cultural differences and communication. They do not often work together as they should. Of such issues, if each group sees common problems, realize them together, and is ready to solve problems together, it will promote the participatory work of all local residents.

- Leaders in three subdistricts at Wiang Haeng district are not strong enough. As a result, it is hard to work together on water resources management, and there is no further development on knowledge received seriously for people in the community to know and understand the collaboration.

- From not having strong community leaders, the community lacks involvement for various functions because there are no significant leaders to initiate operations, and create understanding in the work. This makes most of the people lack awareness, enthusiasm, and attention to develop the community believing that they do not benefit from participating the activities. Therefore, if people in the community cooperate in carrying out any activities in the area, it will help make such activities done with great success [36].

- Therefore, certain government agencies which systematically develop water management model should allow people to participate in the work, listen to public opinions or suggestions, and let them participate in any helpful activities in order to promote understanding among local people.

- A lack of group cooperation from the district level on made it difficult to gather in watershed level. Working on water resources allocation systematically is difficult. As a result, what is important for water management in Wiang Haeng district to carry on concretely is to be grouped together at the district level and will need to work together as a system.

- The implementation of the King's initiatives will help to balance the ecosystem in the area. In other words, new theory agriculture will focus primarily on finding farm water resources to generate sufficient output for a wide range production, a stable source of income to the household, as well as solving the problems of poverty and lack of resources. Thus, promoting new theory agriculture will help farmers realize the benefits of shared water resources in the area. In the end, farmers will participate in the management of water in the area more effectively [37].

Integrated water resources management process: Most of Wiang Haeng district has water management system based traditional wisdom created by selecting heads to monitor water use along the water flowing through the village or as agreed. However, in some areas of Mueang Haeng district, a formal water management was introduced from participating in meetings at the district level and study tours in the area of Long Khot, Phrao district, Chiang Mai province. This helped water user groups, community leaders, and representatives of local governments in Wiang Haeng district form a clearer direction of water management. They noted that Wiang Haeng should have formed an official committee in water management official having a clear structure based on participation of relevant agencies. Local district volunteers are leaders in forming a network and functional structure of the system. This working group will be representing the upstream group, which is Piang Luang subdistrict, midstream group, which is Saen Hai subdistrict, and downstream group, which is Mueang Haeng subdistrict. These groups also include farmer water users who are representatives of each village, Local administrative officers, and representatives of other related agencies such as district agricultural office, Nor Phor Khor 32, and Irrigation and Forestry Department. The integration of water management in the future of Wiang Haeng district was concluded as an overview in the seminar on water management that it was done through creating an understanding of people due to the ethnic diversity in the area, as well as holding meetings to exchange knowledge and share problems between them. After that, the problems or obstacles that cannot be solved in the region were proposed to related agencies, such as Nor Phor Khor 32. The water user network was formed by appointing committee in the subdistrict, village, and district level to manage the water. Meetings will be held at least one time per three months. Moreover, there will be a meeting project to announce guidelines and regulations, set a clear authority of those involved, and establish water management group as well as a chairperson of the district level to coordinate and represent to participate in water management in the basin level group.

\section{Overview of the integration of water resources management in maetaeng sub watershed}

From studying the problems, situation, and condition of water resources management in the Maetaeng watershed area, it was found that in the past Maetaeng watershed management was conducted separately without the integration between community, Subdistrict, and district level. However, after the research project started to study, brainstorm ideas of people in community, Subdistrict, and district level situated between the district areas related to Maetaeng sub watershed. This also included the study tours of the master models of water resources management in Long Khot sub district, Phrao district. When all parties were informed and aware of the problems, situations, and guidelines to water resources management, it was concluded together that the integration for water resources management in Maetaeng sub watershed area must provide all relevant sectors to come together to truly engage in the project both in terms of brainstorming to find ways to solve problems, using watershed areas together, as well as leading to a common practice concretely by integrating all sectors. All sectors of the community, subdistrict, and district level must be aware and willing to come and truly solve problems together. The integrated water resources management in Maetaeng subwatershed should be conducted by creating a strong community. Particularly the community leaders need to play an important role to create greater understanding 
among people in the community to recognize the existing problems together with realizing the value of natural resource conservation through various activities that allow people in the community to meet, discuss, and exchange ideas. The local governments will need to support and participate in hearing problems occurring in their local areas [38]. This will promote closer relation with the community, and solutions on the right spot, especially water issues which will become increasingly more severe both for drought and flooding problems. When people in the community see the sincerity in resolving the issue, most of them are ready to take part in the various operations that help develop or enhance the quality of life focusing on public interests first. As a result, the community will be strengthened and unified, and that would promote cooperation among villages, subdistricts, and districts in the future. In addition to local government, other related agencies-the Irrigation Department, Forestry Department, Water Resources Department, Land Development Department, Nor Pho Khor 32, private sectors, etc -should support and provide assistance to people in various operations such as budget, equipment and facilities, or even sharing new knowledge to help them improve or develop further. For example, they can provide knowledge on building a check dam, agricultural training, organizing study tours in many places to exchange learning experiences with other communities regularly, and conducting projects to protect and conserve the forest areas. We can see that if the community is strengthened, and related agencies take part in various operations, the integration of community networks in the watershed areas of community, subdistrict, and district level would be easy. The existing resources management model would also be developed more concretely and systematically from upstream, midstream to downstream covering three districts-Wiang Haeng, Chiang Dao, and Maetaeng district. Because everyone focuses more on mutual benefits, this helps the management of water resources in Maetaeng subwatershed areas become more effective, which truly leads to integrated management from all sectors (Figure 2).

\section{Policy recommendations}

From the study of water management in Maetaeng subwatershed area in Chiang Mai province, it can be concluded into following points for the government or related agencies to use for development or setting strategies for national water management in the whole as follows.

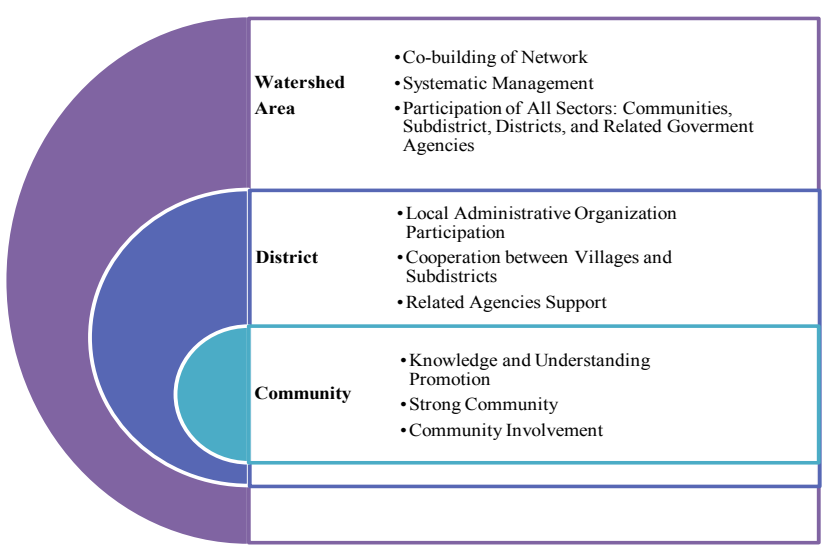

Figure 2: Maetaeng sub watershed Water Management Guideline Starting from Community to District Level by Linking with Watershed Area Network that Involves All Sectors: People, Local Administration Organizations, and Related Public and Private Sectors.
1) The government should have a policy to assist with the allocation of funds to Subdistrict Administration Organizations in each area, and take the water issue seriously by looking at the real problem in the area, encouraging the network to manage water in the area, and collaborating in the project monitoring.

2) Each area of this study said showed that the existing water management system is still based on traditional wisdom. Therefore, the government should help solve the problem in the area rather than only solve the problem at higher level.

3) The government should support local governments financially in doing projects or activities at a village level regarding water management and upstream forest conservation concretely.

4) The public sector or related government agencies must pay attention and support a network of integrated and concrete watershed management. All sectors should come together to play a role in water management, solving problems in common areas, and conserving upstream forest.

5) The government or related agency projects operated in the watershed areas must be truly public hearing, open an opportunity for the watershed management network to participate in the work, and listen to comments or feedbacks from all related sectors prior to the implementation of any project.

\section{References}

1. Kannikar C (1981) People Participation in Economic Development: A Case Study in Saraphi Project, Tha Chang Sub district, Warinchamrap, Ubonrajchathani.

2. National Economic and Social Development Board (1961) The First National Economic and Social Development Plan. Bangkok.

3. National Economic and Social Development Board (1967) The Second National Economic and Social Development Plan. Bangkok.

4. National Economic and Social Development Board (1972) The Third National Economic and Social Development Plan. Bangkok

5. National Economic and Social Development Board (1977) The Fourth National Economic and Social Development Plan. Bangkok.

6. National Economic and Social Development Board (1982) The Fifth National Economic and Social Development Plan. Bangkok.

7. National Economic and Social Development Board (1987) The Sixth National Economic and Social Development Plan. Bangkok.

8. National Economic and Social Development Board (1992) The Seventh National Economic and Social Development Plan. Bangkok.

9. National Economic and Social Development Board (1997) The Eighth National Economic and Social Development Plan. Bangkok.

10. National Economic and Social Development Board (2002) The Ninth National Economic and Social Development Plan. Bangkok.

11. National Economic and Social Development Board (2007) The Tenth National Economic and Social Development Plan. Bangkok.

12. Chiang Mai Water Resources Management Project (2010) Chiang Mai Water Resources Management and Development Plan.

13. Chayut P (2000) Natural Resources and Environment Management based on Community Culture Approach: A Case Study at Ban Mae Sa Mai, Pong Yaeng Subdistrict, Maetaeng District, Chiang Mai Province.

14. Chukiat L (1990) Learning System in Northern Rural Area Research Report.

15. Chukiat $L$ (1991) Teaching Materials of Philosophy and Non-Formal Education Principles.

16. Duangporn P (2005) Water Resources Management: A Case Study at Ban Pong Khrai, Maetaeng District, Chiang Mai Province. 
Citation: Sucharidtham T, Sriwichailamphan T, Matanboon W (2015) Integrated Water Resources Management of Maetang Sub Watershed, Chiang Mai Province. J Glob Econ 3: 150. doi:10.4172/2375-4389.1000150

Page 7 of 7

17. Taweethong H (1984) Community Participation: Policies and Strategies. Bangkok.

18. Summary Document of Khi Lek Municipality (2012) Chiang Mai Province.

19. Summary Document of San Mahaphon Municipality (2012) Chiang Mai Province.

20. Summary Document of Saen Hai Municipality (2012) Chiang Mai Province.

21. Pornthip T (2000) Northern Water Management of Check Dam System. Journal of Economics.

22. Phairat $\mathrm{T}$ (1984) Social Development.

23. Phairat T (1984) Policies and Methods of Public Participation in Current Developmental Strategies.

24. Wanpen S (1986) Historical Development and Irrigation System Management in Northern Thailand.

25. Wirat W (1992) Natural Resources Management: Role of Local Administrative Organization.

26. Somkit B (1995) Principles of Management.

27. Office of the Secretariat to the Upper Ping River Basin Board (2013) Workshop Document for Integrated Ping River Basin Management and Development Plan, Maetaeng Sub watershed
28. Summary Document of Wiang Haeng District (2013) Chiang Mai Province.

29. Surichai W (1987) Lessons from Development Strategies: Education and Employment Research Project. Bangkok.

30. Surichai W (2002) Sustainable Development in Globalization and Directions of Thailand. Bangkok.

31. Summary Document of Guert Chang Subdistrict Administration Organization (2012) Chiang Mai Province.

32. Summary Document of Piang Luang Subdistrict Administration Organization (2013) Chiang Mai Province.

33. Summary Document of Mueang Khong Subdistrict Administration Organization (2013) Chiang Mai Province.

34. Mueang Haeng Subdistrict Administration Organization (2012) Annual Report of Mueang Haeng Subdistrict Administration Organization.

35. Summary Document of Maetaeng Subdistrict Administration Organization (2013) Chiang Mai Province.

36. Cohen MJ, Norman TU (1977) Rural development participation: Concepts and Measures for Project Design Implementation and Evaluation.

37. Fayol H (1949) General and Industrial Management. Pitmand and sons London.

38. Fonaroft A (1966) Community involvement in health systems for primary health care. 